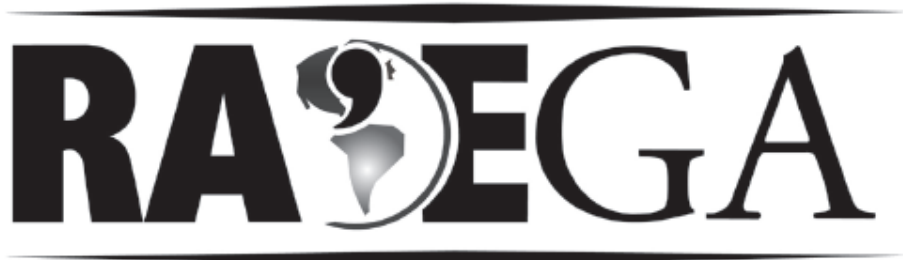

O ESPAÇO GEOGRÁFICO EM ANÁLISE

\title{
PARQUES URBANOS DE GOIÂNIA-GO: PAPEL SOCIAL E POTENCIAL TURÍSTICO
}

\author{
Urban parks from Goiânia-GO: social role and potential \\ tourist
}

\author{
Carolina Ferreira da Costa STREGLIO ${ }^{1}$ \\ Ivanilton José de OLIVEIRA ${ }^{2}$
}

\section{RESUMO}

Nas últimas décadas, o crescente movimento de proteção ambiental vem interferindo na configuração das cidades, conjuntura em que se destaca a criação de parques urbanos. As funções ecológicas e sociais atribuídas a essas áreas verdes as tornam objetos de estudo de grande relevância para compreender a dinâmica urbana atual, contexto em que se insere o município de Goiânia. Considerando esses atributos, bem como o caráter distintivo que os parques estabelecem na paisagem urbana, o que permite relacioná-los também ao turismo, este artigo tem como objetivo analisar o desempenho dos parques urbanos na dinâmica de Goiânia, para, com base nessa análise, verificar o seu potencial turístico.

Palavras Chave: Parques Urbanos; Goiânia; Potencial turístico.

\footnotetext{
1 Bacharel em Geografia, habilitada em Análise Ambiental pelo Instituto de Estudos Socioambientais (UFG). Mestranda, pelo Programa de Pós-Graduação em Geografia do Instituto de Estudos Socioambientais (UFG). E-mail: ocorreio@ymail.com

2 Licenciado e Bacharel em Geografia pela UFG, Mestre e Doutor em Geografia pela USP. Professor Adjunto do Instituto de Estudos Socioambientais (UFG) da Universidade Federal de Goiás (UFG).

E-mail: ivanilton.oliveira@gmail.com
} 


\begin{abstract}
In recent decades, the growing environmental protection movement has been interfering in the configuration of cities, conjuncture which it detach the creation of urban parks. The ecological and social functions assigned to these green areas make them objects of study of great relevance to understand the current urban dynamics, context in which it enters the city of Goiania. Considering these attributes, as well as the distinctive feature that parks in the urban landscape, which allows them to relate also to tourism, this article has as objective to analyze the performance of urban parks in the dynamics of Goiânia for based on this analysis, to verify the their tourist potential.
\end{abstract}

Keywords: Urban Parks. Goiânia. Tourist potential.

\title{
INTRODUÇÃO
}

A preservação dos recursos naturais e a manutenção da qualidade de vida assumiram posições de destaque na administração pública, nas últimas décadas, haja vista a frequência e intensidade dos casos de degradação ambiental, a ameaça de extinção de diversos recursos naturais e o crescente anseio da sociedade por ambientes ecologicamente saudáveis.

Partindo dessa conjuntura, uma das tendências observadas na gestão pública de diversas cidades brasileiras tem sido a criação de parques urbanos, tendo em vista que estes não apenas contribuem para a conservação ambiental, ou seja, a utilização racional dos recursos naturais disponíveis, mas também tornam mais agradável o dia-a-dia de quem reside nas grandes cidades.

A figura dos parques comumente sugere áreas de vegetação abundante, com lagos e animais silvestres, cenários que os tornam ambientes propícios ao lazer, à prática esportiva ou à simples contemplação, e possibilitam uma série de benefícios, tais como a redução da poluição e o equilíbrio do índice de umidade do ar (este apenas quando há corpos hídricos significativos), a proteção das nascentes e mananciais, a moderação do macro e micro clima urbano e a manutenção da biodiversidade (NUCCI, 2001; SORENSEN, 1998).

Considerando o caráter distintivo que os parques estabelecem na paisagem urbana, outro elemento que pode relacionar-se a esses ambientes é 
o turismo. Segundo Furegato (2005), a atividade turística em áreas verdes urbanas pode decorrer de fatores como valorização cultural, marketing, situação geográfica favorável, modismo, além do vínculo afetivo que se estabelece entre os moradores e o seu meio ambiente urbano. Entretanto, a mesma autora lembra que apesar de serem utilizados pelo turismo, geralmente, esses parques são construídos em primeira instância, para os habitantes locais.

Neste sentido, Yázigi (2002) acrescenta que a paisagem lato sensu natural e urbana - deve ser preservada, antes de qualquer coisa, devido sua importância ao habitante local, e só depois ao turista, visto que esta paisagem se constitui como essência cotidiana dos habitantes de uma cidade.

As diversas funções ecológicas e sociais atribuídas aos parques urbanos tornam esses espaços objetos de estudo de grande relevância para a compreensão da dinâmica urbana na atualidade, contexto em que se insere o município de Goiânia.

Elaborado pelo engenheiro urbanista Armando de Godoy, em meados dos anos de 1930, o projeto de construção de Goiânia baseou-se no modelo das cidades-jardim inglesas, o que refletiu na criação de diversas áreas verdes pela cidade. Essa característica, ainda hoje percebida na paisagem da cidade, contribuiu para tornar Goiânia a cidade com a área urbana mais verde do país (MARTINS JÚNIOR, 2007).

Atualmente, Goiânia possui 24 parques urbanos, distribuídos por diversas regiões da cidade. Sem embargo, é importante ressaltar que a crescente valorização das áreas verdes, e por conseguinte, o interesse do mercado imobiliário por esses espaços, tem promovido o favorecimento de determinados parques em detrimento de outros.

Outro aspecto que também interfere na dinâmica desses espaços é a atividade turística. Os parques urbanos goianienses são divulgados como cartões postais da cidade, mas existe uma infraestrutura destinada ao suporte da atividade turística nesses espaços? Considerando a premissa de que uma cidade boa o suficiente para os próprios habitantes, realmente é excepcional ao 
turismo (YÁZIGI, 1996), pode-se dizer que os parques urbanos de Goiânia são potencialmente turísticos?

Tendo em vista esses questionamentos, bem como a diversidade de valores e atributos relacionados aos parques goianienses, este artigo tem como objetivo a análise do desempenho dos parques na dinâmica urbana de Goiânia, considerando essencialmente o nível de satisfação de seus usuários quanto aos recursos oferecidos por esses espaços, ponderando ainda fatores como a infraestrutura e a gestão dos parques, para, com base nessa análise, verificar o potencial turístico dos parques urbanos de Goiânia.

Com relação aos métodos e procedimentos utilizados para a operacionalização deste trabalho, a princípio, realizou-se uma revisão teórica e conceitual, a fim de apresentar subsídios à contextualização e análise dos parques urbanos de Goiânia. Como estudos de casos, foram selecionados três parques - o Bosque dos Buritis, o Parque Flamboyant e o Parque da Lagoa onde foram executados trabalhos de campo com vistas à observação, diagnóstico da infraestrutura e aplicação de questionários aos usuários. E, a partir dessas informações, realizou-se a interpretação, análise e representação gráfica e tabular dos dados gerados, o que permitiu avaliar o desempenho dos parques na dinâmica de Goiânia, assim como o seu potencial turístico.

\section{O QUE É UM PARQUE URBANO?}

Para compreendermos a dinâmica que envolve os parques de Goiânia é importante iniciar essa análise entendendo o que caracteriza, especificamente, um parque urbano, tendo em vista que a palavra 'parque' pode admitir vários outros adjetivos, tais como aquático, infantil, de diversões etc., que designam ambientes distintos.

Segundo Lima (1994), os parques urbanos são áreas verdes, com função ecológica, estética e de lazer, mas com uma extensão maior que as praças e os jardins públicos. No mesmo sentido, Kliass (1993, p. 19) os define como "espaços públicos com dimensões significativas e predominância de elementos naturais, principalmente cobertura vegetal, destinado à recreação". 
$\mathrm{Na}$ definição do Sistema Nacional de Unidades de Conservação da Natureza - SNUC, há a figura do Parque Natural Municipal, unidade de conservação criada por um município, cujo objetivo básico é

a preservação de ecossistemas naturais de grande relevância ecológica e beleza cênica, possibilitando a realização de pesquisas científicas e o desenvolvimento de atividades de educação e interpretação ambiental, de recreação em contato com a natureza e de turismo ecológico (BRASIL, 2000).

Macedo; Sakata (2003, p. 14), por sua vez, consideram como parque

todo espaço de uso público destinado à recreação de massa, qualquer que seja o seu tipo, capaz de incorporar intenções de conservação e cuja estrutura morfológica é auto-suficiente, isto é, não é diretamente influenciada em sua configuração por nenhuma estrutura construída em seu entorno.

Entretanto os mesmos autores ressaltam que

não existe consenso a respeito da dimensão, do grau de isolamento em relação ao entorno e da quantidade de equipamentos necessários para configurar um parque [...] muitos dos atuais parques de pequeno porte não passam realmente de praças de vizinhança, sendo denominados parques em virtude da falta de consenso sobre o assunto entre os especialistas, dentro e fora do poder público. (MACEDO; SAKATA, 2003, p. 15).

Tendo em vista essas considerações, pode-se notar que os conceitos aqui relacionados se atem basicamente a dois aspectos referentes aos parques urbanos: sua dimensão espacial e a diversidade de funções ecológicas e sociais que estes podem desempenhar na cidade. Como não se tratam de parâmetros bem delimitados, neste trabalho serão apreciados como parques aqueles assim definidos pela Agência Municipal do Meio Ambiente - AMMA, órgão responsável pela criação, administração e proteção de parques, bosques e demais áreas verdes de Goiânia.

\section{GOIÂNIA E OS PARQUES URBANOS}

Goiânia foi construída em um momento em que o Brasil passava por grandes transformações políticas. Com a Revolução de 1930, ascendeu ao 
poder Getúlio Vargas. E em Goiás, com a vitória do movimento revolucionário, Pedro Ludovico Teixeira foi nomeado interventor.

Enquanto esteve no governo, Ludovico procurou inserir Goiás na nação, incentivando o progresso econômico do estado e integrando-o à economia do país. Nesta conjuntura, surgiram as discussões para a mudança da capital, com argumentos relacionados desde a questão da topografia, da dificuldade de comunicação e acesso, até as condições de higiene e salubridade da cidade de Goiás, a até então capital do estado.

O processo de mudança da capital teve início em 20 de dezembro de 1932, quando o interventor assinou o Decreto № 2737/1932, nomeando uma comissão para a escolha do local. Então, no dia 04 de março de 1933, foi apresentado um estudo selecionando a cidade de Campinas, tendo em vista que esta localidade encontrava-se no ponto central geográfico e demográfico do estado, com uma topografia adequada e promissora, em uma zona com maior desenvolvimento, com um vasto perímetro de terras produtivas e cobertas por uma excelente mata (FERREIRA, 2003).

O primeiro projeto de Goiânia foi elaborado pelo o arquiteto-urbanista Atílio Correa Lima, inspirado na escola francesa de urbanismo do inicio do século XX, influencia que atribuiu funcionalidade ao traçado da capital. Entretanto, antes de concluir o projeto, Atílio rompeu o contrato com o governo de Goiás, sendo então substituído pelo engenheiro urbanista Armando de Godói, que deu continuidade ao plano, mas seguindo orientação do modelo das cidades-jardim inglesas (DAHER, 2009).

Em síntese, as cidades-jardim, criadas por Ebenezer Howard constituíam agrupamentos equilibrados, que usufruíam das vantagens do campo e da cidade evitando as deficiências de ambos. Assim sendo, dentre as principais preocupações de Howard, estava a necessidade de dotar a trama urbana de extensas áreas verdes constituídas de jardins, parques e bulevares, com vista a salubridade da cidade e possibilitar o acesso da população precariamente instalada nas cidades industriais então existentes à moradias de baixo custo e alta qualidade ambiental (OTTONI, 1996). 
No plano original de Goiânia Attílio Corrêa Lima citou a criação de vários parques e áreas verdes, tais como: o Parque dos Buritis, o Bosque dos Bandeirantes, os Parques Lineares Capim Puba e Botafogo, o Parque Paineira, o Parque Aquático Jaó e o Zoológico (MARTINS JÚNIOR, 1996). Mas, desde o surgimento de Goiânia até os dias atuais, muitas transformações ocorreram no ordenamento e na dinâmica da cidade. Mudanças que também se estenderam aos parques encontrados hoje na capital.

Entre a década de 1930 e 1990, muitas das áreas verdes de Goiânia foram extintas com vistas à expansão do aglomerado urbano: o Bosque dos Bandeirantes passou a ser o Lago das Rosas; uma parte do Parque Capim Puba foi transformada na antiga Rodoviária, outra parte em uma praça e outra em uma subestação da Companhia Energética de Goiás (Celg); a área ocupada pelo Parque Paineira foi transferida para empresas estatais (clubes da Celg, Telegoiás e Saneago ${ }^{3}$ ); e, a área do Parque Linear Capim Puba foi ocupada por residências, assim como ocorreu com o Parque Linear Botafogo (Ibidem).

Essa situação é reflexo da omissão ou inoperância dos gestores públicos. De acordo com o documento intitulado "Resgate do Berço Ecológico de Goiânia",

até dezembro de 1992, o órgão [encarregado da fiscalização ambiental] funcionava em duas salas acanhadas no Centro Livre de Artes do Bosque dos Buritis; não possuía a mínima estrutura para o funcionamento e cumprimento das suas competências constitucionais [...] contava com apenas três servidores no seu quadro; a linha telefônica era emprestada da Secretaria de Cultura; não existia a fiscalização ambiental com o conseqüente poder de polícia e nenhum fiscal de postura municipal jamais havia aberto um processo sequer sobre agressão ambiental em toda a história da cidade de Goiânia. Esta ausência de um órgão ambiental foi decisiva para que Goiânia tivesse o seu patrimônio ambiental violentamente dilapidado: somente no perímetro delimitado pelo Plano Original da Cidade, aprovado pelo Decreto-Lei 90-A, de 30.07.38, perderam-se 3,5 milhões de $\mathrm{m}^{2}$ de áreas públicas verdes (GOIÂNIA, 2007, p. 7).

\footnotetext{
${ }^{3}$ Telecomunicações de Goiás S.A. (Telegoiás) e Saneamento de Goiás S.A. (Saneago).
} 
Este relato, redigido por Osmar Pires Martins Júnior, então Secretário Municipal do Meio Ambiente, remete à situação encontrada pelo mesmo no início do mandato de Darci Accorci como prefeito de Goiânia, em 1993. Nesta gestão o poder público municipal utilizou-se do título concedido a Goiânia, que a considerou uma das cidades que mais investiu na qualidade de vida de sua população, para orientar seus discursos no sentido de afirmar o epíteto de "cidade ecologicamente correta", que se transformou em símbolo dessa administração (ARRAIS, 2001).

Neste período, um dos principais programas desenvolvidos pela Secretaria Municipal do Meio Ambiente - SEMMA foi o resgate das áreas verdes de Goiânia. Projeto em que foram contemplados os Parques Areião e Botafogo, bem como o Jardim Botânico e os Parques Liberdade, Carmo Bernardes e Vaca Brava, que não faziam parte do Plano Original da cidade (GOIÂNIA, 2007).

$\mathrm{Na}$ administração seguinte, iniciada em janeiro de 1997, Nion Albernaz deu seguimento a causa ecológica, mas agora considerando Goiânia como a "cidade das flores". Neste contexto, a prefeitura procurou exaltar a qualidade de vida da cidade e promover a idéia de que Goiânia revestia-se de flores, mesmo que na verdade esta realidade se restringisse a poucas regiões da cidade, especialmente as centrais (ARRAIS, 2001).

Até janeiro de 2005, dos seis parques totalmente implantados em Goiânia, apenas um se localizava fora das regiões sul e central da cidade, o Parque Gentil Meireles. Foi quando Iris Rezende tornou-se prefeito da capital, e iniciou a implantação de diversos parques e bosques, atingindo em seu segundo mandato um total de 22, além daqueles que ainda se encontravam em fase de implantação.Até o início de 2011, já sob a gestão de Paulo Garcia, Goiânia passou a conter parques distribuídos por várias regiões da cidade, como é possível observar na figura 1. 


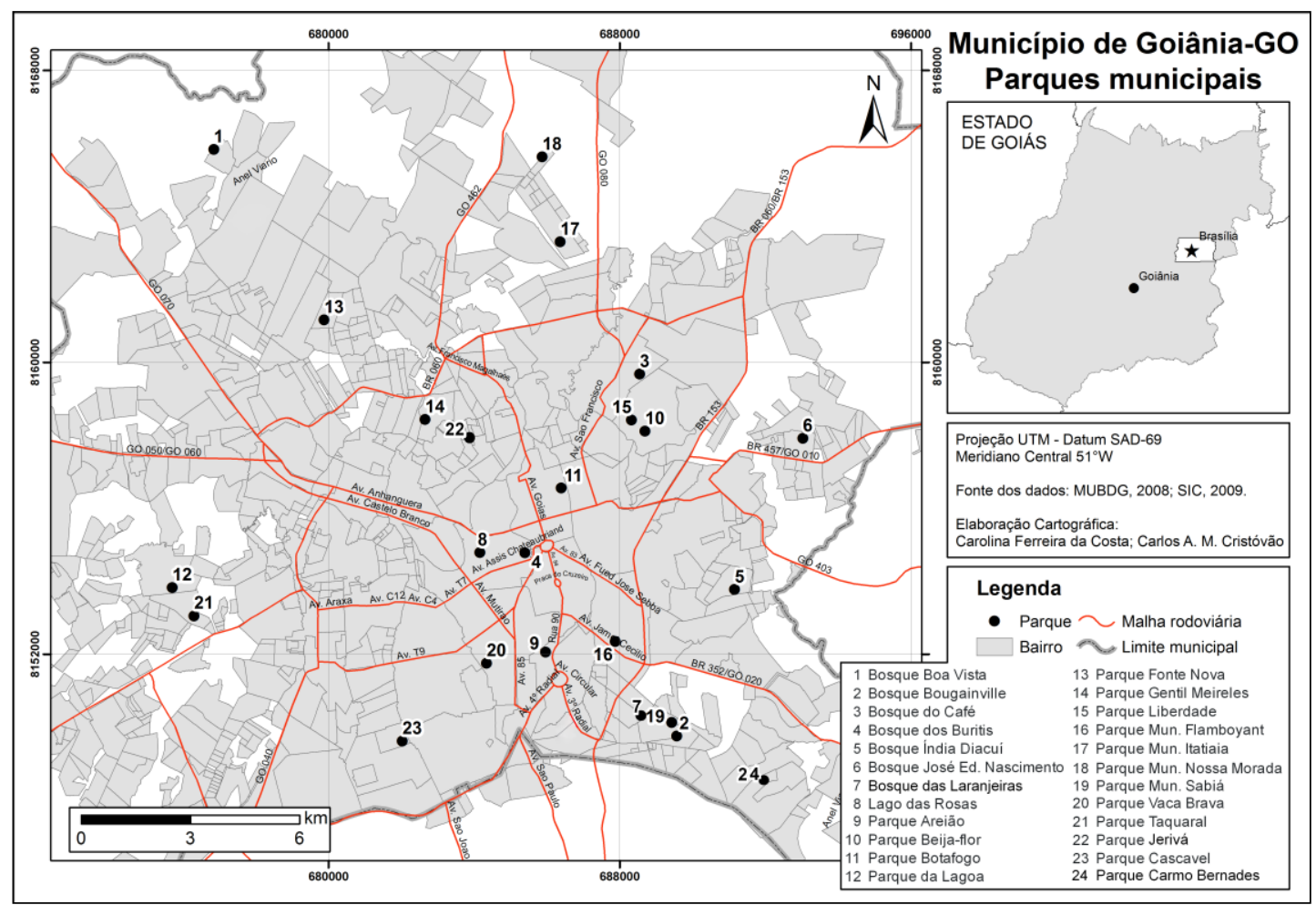

Figura 1 - Mapa dos parques urbanos de Goiânia.

\section{PARQUES URBANOS DE GOIÂNIA: INFRAESTRUTURA, GESTÃO E DESEMPENHO NO COTIDIANO DA POPULAÇÃO LOCAL}

A criação de parques em diversas regiões de Goiânia tem possibilitado que mais áreas verdes da cidade sejam preservadas e um maior número de habitantes desfrute dos benefícios promovidos pela implantação dos parques. Entretanto, para que essas áreas verdes cumpram as diversas funções que lhe são atribuídas, a conservação e manutenção de todos os elementos que compõem uma praça ou um parque devem merecer atenção continuada dos órgãos públicos que gerenciam essas áreas e da população que as utilizam. Pois o uso público de uma área verde está intimamente ligado à manutenção, conservação e segurança que esta área recebe (GUZZO, 1998). 
Tendo em vista essa condição, Guzzo (1998) complementa que a segurança de uma área verde na cidade advém de seu uso constante pela população e de uma Guarda Municipal que seja mais educativa que punitiva. Sendo que esse uso ocorrerá se a área estiver dotada de iluminação eficiente, equipamentos funcionando, gramados podados, árvores de copas altas e muitos outros itens relacionados à conservação e manutenção dos elementos existentes nesse espaço, ou seja, sua infraestrutura.

De acordo Zmitrowicz e De Angelis Neto (1997), a infraestrutura urbana pode ser conceituada como um sistema técnico de equipamentos e serviços necessários ao desenvolvimento das funções urbanas, que podem ser vistas sob os aspectos sociais, econômicos e institucionais. Embora possam ser admitidas algumas variações, definidas conforme especificidades locais, esse mesmo conceito também pode ser aplicado aos parques urbanos, considerando-se que eles devem apresentar uma infraestrutura básica necessária ao desenvolvimento das funções sociais e ambientais que the são inerentes, como, por exemplo, iluminação, assentos, lixeiras, equipamentos diversos destinados a atividades de lazer, dentre outros.

Além da infraestrutura, outro aspecto importante na configuração dos parques refere-se à forma de administração dessas áreas. Conforme Loboda; De Angelis (2005), os espaços públicos quando banalizados ou relegados ao esquecimento se transformam em áreas de crescimento natural de mato, cedem lugar a estacionamentos, além de se tornarem território de "desocupados". Assim sendo, percebe-se que os benefícios sucedidos da implantação dos parques urbanos acabam condicionados ao estabelecimento de infraestrutura e manutenção adequadas, o que depende da gestão pública.

Tendo em vista essas considerações, a seguir, serão analisados 0 Bosque dos Buritis, o Parque Flamboyant e o Parque da Lagoa, identificando, sempre que possível, correlações entre sua localização, a infraestrutura implantada e o modo como estes espaços estão sendo geridos, a fim de verificar seu desempenho junto à população local, bem como o potencial turístico desses parques. 


\section{Bosque dos Buritis}

O Bosque dos Buritis, localizado no Setor Central de Goiânia, possui cerca de $124.800 m^{2}$ e foi instituído pelo Decreto-Lei no $90 \mathrm{~A}$, de 30 de julho de 1938, que o designou como um espaço livre, inalienável, dedicado ao lazer e à preservação ambiental (GOIÂNIA, 2007).

Apesar dessa designação, nas décadas seguintes à sua criação, o bosque passou por um intenso processo de dilapidação de sua área verde, que resultou em uma redução de aproximadamente $70 \%$ em relação a sua área original. Diante desse cenário de degradação, a partir da década de 1990 foram realizadas diversas reformas e intervenções visando recuperar o espaço do parque, o que permitiu transformá-lo, hoje, em um dos cartões postais de Goiânia (lbidem).

Atualmente, o Bosque dos Buritis é composto por três lagos, um orquidário, um espaço para eventos, uma pista de caminhada, um parque infantil, uma estação de ginástica, quiosques, um mirante e caminhos internos, além de uma exuberante vegetação que se destaca na paisagem da capital (figura 2).

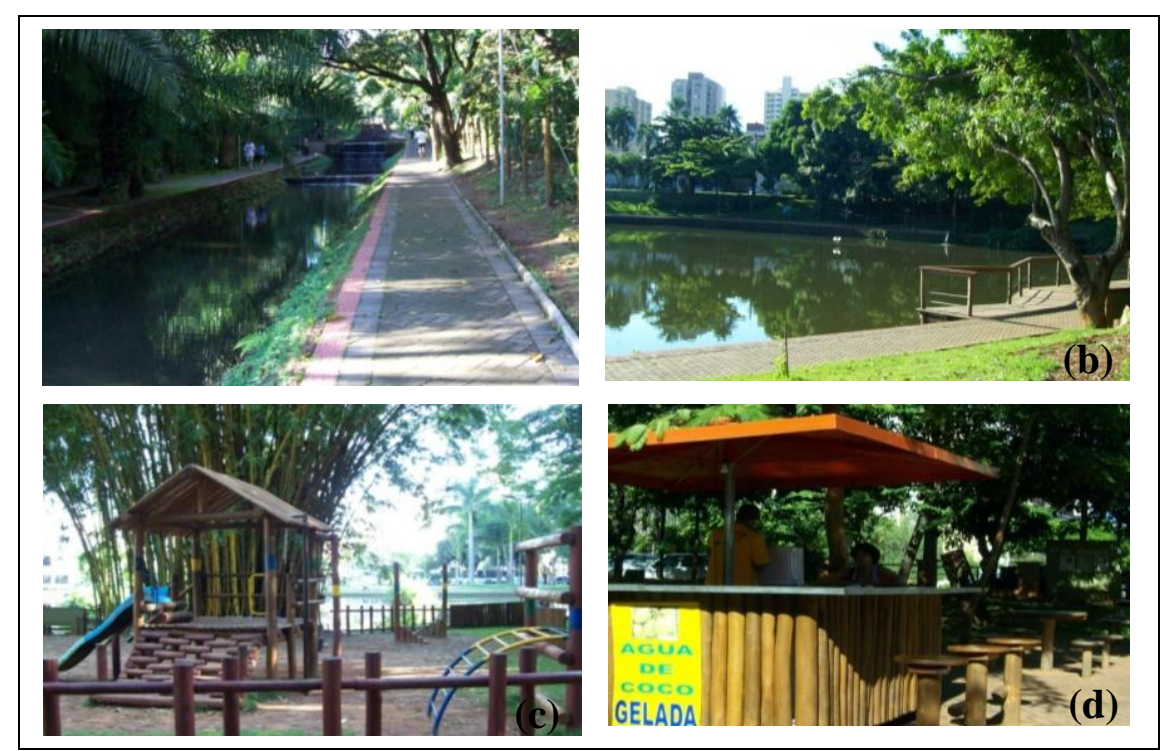

Figura 2: Bosque dos Buritis - pista de caminhada (a), lago (b), parque infantil (c), e quiosque (d). Fonte: Carolina Ferreira da Costa, 2009. 
Além disso, outro elemento importante são as placas indicativas instaladas por todo o ambiente, visto que possibilitam a orientação, e, portanto o maior conhecimento e aproveitamento da infraestrutura do bosque (figura 3 ).

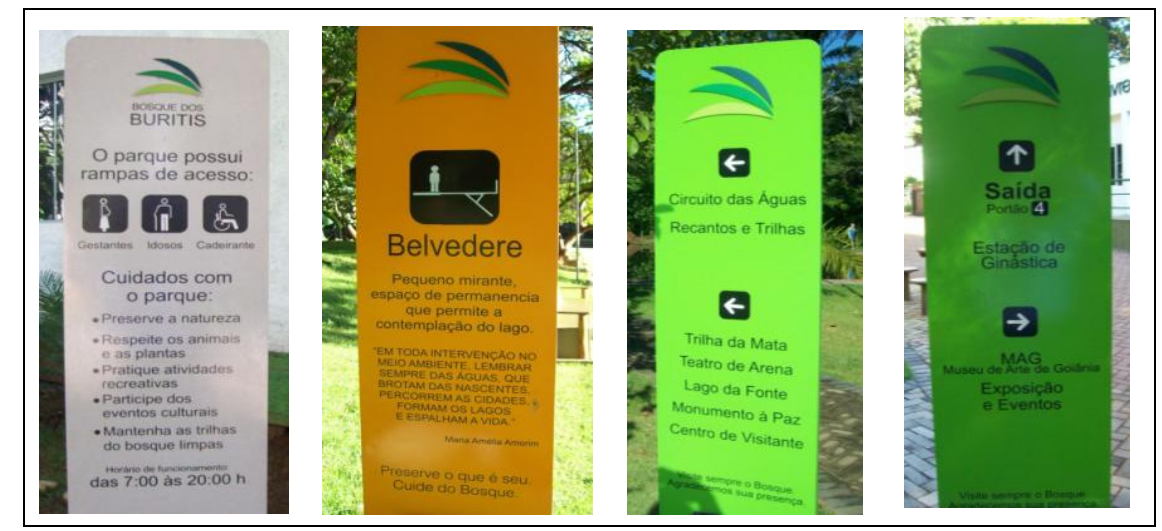

Figura 3: placas que auxiliam na orientação pelo Bosque dos Buritis.

Fonte: Carolina Ferreira da Costa, 2009.

Outro aspecto que facilita o acesso da população a esta área verde refere-se à sua localização no Setor Central da cidade. Por meio de questionários aplicados aos visitantes do bosque, verificou-se que $60 \%$ das pessoas pesquisadas não residiam nas proximidades do parque. $\mathrm{E}$, dentre essas, cerca de $50 \%$ se deslocaram de seus bairros motivados pela beleza daquela paisagem.

Quando questionados sobre a qualidade da infraestrutura do Bosque dos Buritis, $80 \%$ dos visitantes a consideraram boa ou ótima; $50 \%$ dos quais disseram, ainda, não haver nada o que melhorar no espaço do parque, o que indica um alto nível de satisfação por parte dos usuários.

A manutenção do Bosque dos Buritis é realizada por uma gerência própria, subordinada a AMMA. Essa equipe, composta por doze funcionários, executa serviços como o plantio de mudas, a poda da grama e a limpeza do lago, bem como de todo o parque. Segundo esses servidores, o principal problema enfrentado refere-se ao comportamento de alguns visitantes, que lançam lixo em local inadequado e praticam atos de vandalismo, quebrando equipamentos. Nesse contexto, insere-se o trabalho da Guarda Municipal, que auxilia na manutenção do bosque, identificando condutas indevidas e orientando os usuários. 


\section{Parque Flamboyant}

Inaugurado em 15 de setembro de 2007, o Parque Flamboyant localizase na região sudeste de Goiânia, em uma área de aproximadamente 125.570 $\mathrm{m}^{2}$, que no passado pertenceu a Fazenda Botafogo e foi tombada através do Decreto no 158, de 24 de janeiro de 2000 (HAMU, 2008). Neste espaço, onde se encontram diversas nascentes, dentre elas a do Córrego Sumidouro, afluente do Córrego Botafogo, foram instalados dois lagos, pontes de madeira, mirante, parque infantil, ciclovia, pista de cooper, estação de ginástica, caminhos internos, além de um jardim japonês (figura 4).

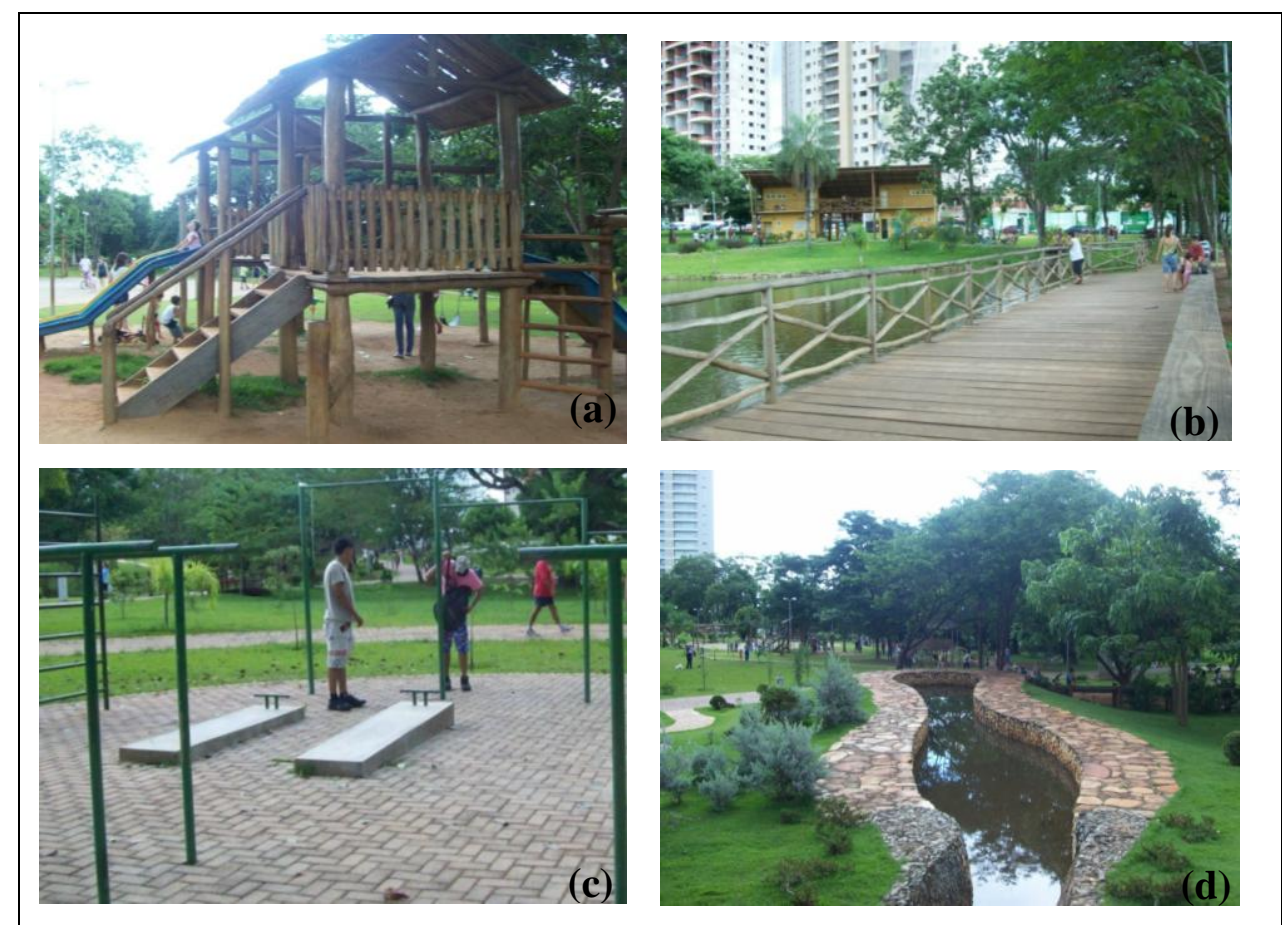

Figura 4: Parque Flamboyant - parque infantil (a), belvedere (b), estação de ginástica (c) e jardim japonês (d). Fonte: Carolina Ferreira da Costa, 2009.

Estabelecido no Jardim Goiás, bairro que já constituía "um dos centros mais importantes de desenvolvimento econômico da capital" (Ibidem), esse parque reuniu de forma admirável os elementos arquitetônico, paisagístico e ecológico, tornando a região bastante visada pelo mercado imobiliário, que vem 
construindo diversos edifícios nas suas imediações. Essa tendência promete ao futuro morador aliar a qualidade de vida, representada pelo parque, à residências de alto padrão.

Tendo em vista a beleza dessa área verde, verificou-se, por meio da aplicação de questionários, que $87,5 \%$ dos entrevistados se deslocaram de outras regiões de Goiânia, e inclusive de outras cidades, para visitar o parque. Quanto à qualidade da infraestrutura, todos os visitantes consideraram-na boa ou ótima; e metade dos entrevistados disse que não havia o que melhorar no espaço do parque.

Assim como no Bosque dos Buritis, a manutenção do Parque Flamboyant é realizada por uma gerência própria. Para essa equipe, composta por seis funcionários, o principal problema se refere à má conduta dos próprios usuários. Segundo o relato de funcionários, devido à proximidade com 0 Estádio Serra Dourada, em dias de jogo o parque é tomado por torcedores, que quebram placas e realizam pichações. Segundo relatos dos funcionários do parque, nestas situações nem mesmo a Guarda Municipal é suficiente, sendo necessário também o apoio da Polícia Militar para conter os depredadores.

\section{Parque da Lagoa}

O Parque da Lagoa ou Parque João Carlos Fernandes de Oliveira, assim denominado em homenagem a uma conhecida liderança comunitária do Parque Industrial João Braz, foi inaugurado em 26 de junho de 2008, em uma área de aproximadamente $37.250 \mathrm{~m}^{2}$, localizada numa área periférica da região oeste da capital (COSTA, 2008).

Segundo a Prefeitura, durante os anos de 1980 o manancial existente nessa área abrigava uma rica fauna aquática e ajudava a elevar a qualidade de vida da população da região. Entretanto, em função de intervenções de impacto negativo, o local foi aterrado na década de 1990, transformando-se em um grande matagal que passou a abrigar um depósito de lixo.

Tendo em vista essa situação, em 2007 a AMMA iniciou um processo de recuperação desse espaço, executando a limpeza completa do terreno, 
demarcação da área da lagoa e perfuração da mina que dava origem ao manancial, bem como o projeto de recuperação florística da área (lbidem). Hoje, como podemos observar na figura 5, o parque abriga uma lagoa, um parque infantil, uma pista de caminhada, uma estação de ginástica, um campo de futebol, uma pista de skate e uma quadra poliesportiva.

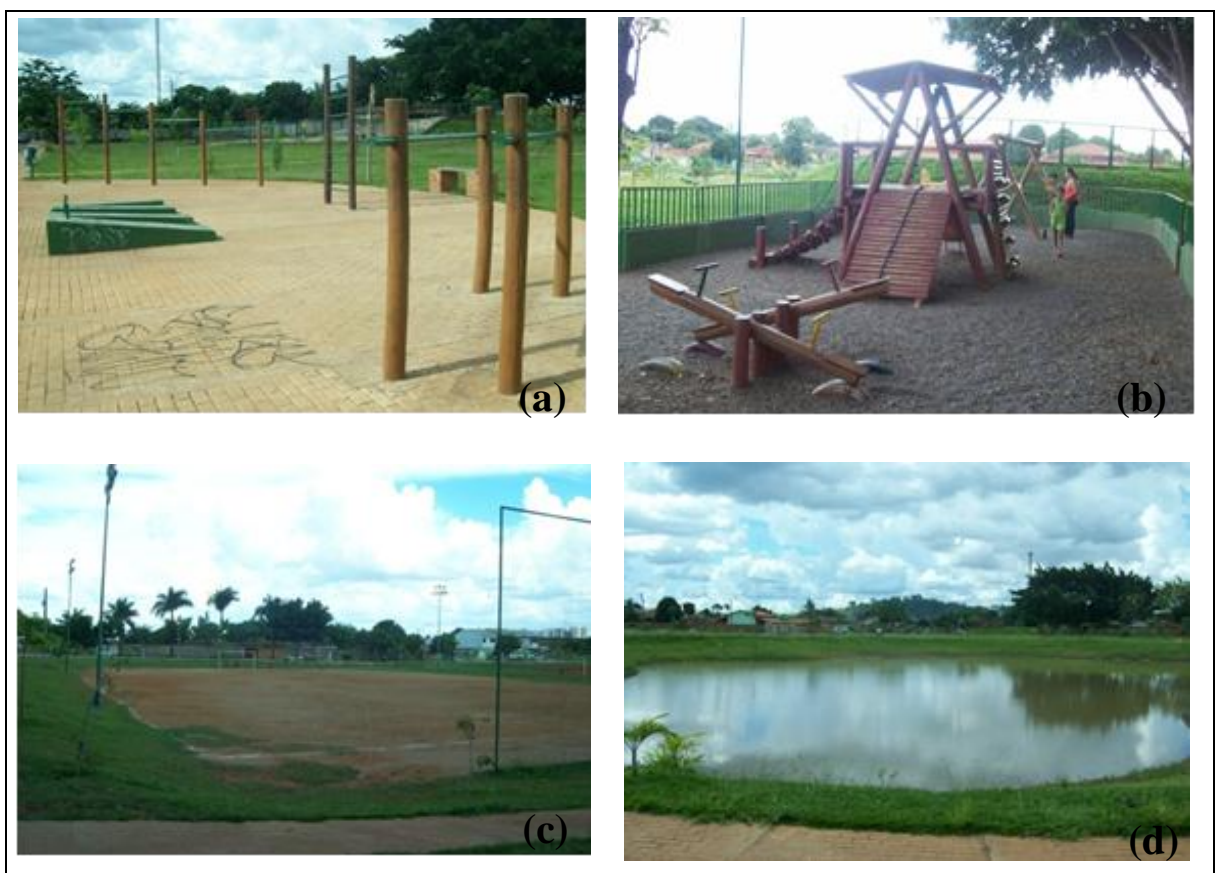

Figura 5: Parque da Lagoa - estação de ginástica (a), parque infantil (b), quadra poliesportiva (c) e a lagoa (d). Fonte: Carolina Ferreira da Costa, 2009.

Comparando o Parque da Lagoa ao demais (Bosque dos Buritis e Parque Flamboyant), observa-se que, além de abranger uma área bem menor, - parque também se distingue com relação à sua cobertura vegetal. Atualmente, a área verde é composta principalmente por vegetação rasteira, pois as árvores plantadas no projeto de recuperação florística ainda estão em fase de desenvolvimento. Estes aspectos tornam o espaço, considerado pela AMMA como parque municipal, bem semelhante a uma praça.

Apesar disso, uma parcela significativa dos usuários, que responderam ao questionário desta pesquisa, mostrou-se satisfeita com o Parque da Lagoa. Referente à sua infraestrutura, por exemplo, $60 \%$ consideraram boa ou ótima. Quanto às eventuais melhorias, $40 \%$ dos entrevistados consideraram desnecessária qualquer mudança, e $60 \%$ sugeriram a intensificação do 
policiamento - e, destes, aproximadamente $65 \%$ também citaram o acréscimo de iluminação.

Referente à sua gestão, o Parque da Lagoa também se distingue dos demais parques analisados, visto que não possui uma administração própria. Sua manutenção é realizada diretamente pela AMMA, que disponibiliza três equipes para percorrerem os parques de menor porte, executando os serviços necessários.

\section{PARQUES URBANOS DE GOIÂNIA: POTENCIAL TURÍSTICO}

Como se propôs no início deste artigo, a análise referente ao potencial turístico dos parques urbanos goianienses considerará, essencialmente, 0 pressuposto de que uma cidade boa o suficiente para os próprios habitantes, realmente é excepcional ao turismo (YÁZIGI, 1996). Entretanto, é importante ressaltar que

Cualquier espacio geográfico es un potencial espacio turístico y tiene la capacidad de ofrecer ciertos bienes y servicios turísticos; sin embargo, no todos tienen la infraestructura necesaria, ni albergan al volumen suficiente de turistas como para poder ser considerado tales (ALVAREZ, 1999, p. 25).

Observando, ainda, que

o que diferencia o lugar turístico da atualidade de outros lugares (inclusive aqueles considerados potencialmente turísticos), é a presença do turista e não, simplesmente, a existência de infraestruturas típicas de um uso turístico, como meios de hospedagem e infraestrutura de lazer (CRUZ, 2003, p. 8).

Como mencionado no item anterior, os três parques analisados (Bosque dos Buritis, Parque Flamboyant e Parque da Lagoa), de modo geral, foram bem avaliados pelos seus usuários. E quando questionados se os parques constituíam atrativos turísticos, a maioria dos visitantes admitiu a referida atratividade. 
De acordo com os usuários do Bosque dos Buritis, o atributo turístico relacionado a essa área verde, decorre da beleza do ambiente, dos diversos recursos naturais ali reunidos, da história concernente àquele espaço e do interesse de "pessoas de fora" em conhecer o parque. No Parque Flamboyant, além da beleza e tranqüilidade, os visitantes também indicaram a falta de outros atrativos turísticos na capital para justificar o interesse turístico suscitado pelas áreas verdes goianienses. Já no Parque da Lagoa, também houve aqueles que destacaram sua beleza, mas a maioria das respostas relacionou a atratividade turística ao fato de pessoas se deslocarem de outros bairros para visitar o referido parque.

Os itens anteriormente mencionados realmente distinguem esses ambientes do todo urbano, o que os tornam potencialmente turísticos, pois o reconhecimento da população local quanto a esses atributos indica que esses espaços já possuem um valor distinto, relevante no seu cotidiano. Trata-se do primeiro passo para despertar o interesse dos visitantes e agregar valor turístico a essas áreas, porém, não é o suficiente para o estabelecimento da atividade turística.

A princípio, o instrumento fundamental na determinação e seleção das prioridades para a evolução harmoniosa do turismo é o planejamento (RUSCHMANN, 1997), atividade a qual se deve somar "uma gestão integrada dos aspectos físico-territoriais, ambientais, político-administrativos, econômicos e sociais" (ALMEIDA, 2004).

Em Goiânia, essas atribuições competem a Secretaria Municipal do Turismo - SEMTUR, mas, considerando o turismo relacionado às áreas verdes da capital, percebe-se que as atividades desse órgão ainda se mostram incipientes.

Segundo seus próprios funcionários, na SEMTUR não há qualquer projeto específico de promoção dos parques urbanos goianienses. Existem apenas algumas ações de publicidade, que, além de divulgar os parques como atrativos turísticos, destacam a condição de capital brasileira com melhor qualidade de vida e o título de área urbana mais verde do país. 
Dentre todos os parques da capital, somente o Bosque dos Buritis foi contemplado com a construção de um Centro de Atendimento ao Turista CAT, porém, trata-se de um local com pouco destaque no parque, situando-se em uma área afastada das principais vias de circulação dos visitantes, e seu funcionamento não abarca os fins de semana.

No CAT do Bosque dos Buritis são disponibilizados aos turistas o guia Curta Mais, que resulta de uma produção terceirizada que apresenta os principais eventos, opções de lazer, compras, hospedagem e alimentação, dentre outros elementos de interesse ao turista; e um mapa elaborado pela SEMTUR, no qual são destacados os principais centros comerciais, os hotéis, os museus, os teatros, a arquitetura Art Déco e os parques urbanos, com exceção daqueles inaugurados após junho de 2008, como é o caso do Parque da Lagoa.

Se por um lado, espaços como o Bosque dos Buritis e o Parque Flamboyant ainda necessitam de alguns ajustes para possuírem a consideração de local turístico e atenderem bem ao turista, outras áreas verdes como o Parque da Lagoa servem apenas para incrementar as estatísticas que promovem Goiânia como capital ambiental. A infraestrutura e a gestão dos parques de bairros periféricos mostram-se nitidamente inferiores àqueles que se localizam em setores nobres, assim sendo, a possibilidade de se estabelecer atividade turística nessas áreas é significativamente menor.

Tendo em vista que

os espaços são diferentemente valorizados pelas sociedades, em função das possibilidades técnicas que determinam sua utilização, de fatores políticos, econômicos e, também culturais, todo espaço do planeta pode ser considerado espaço do turismo (CRUZ, 2003, p. 12)

Entretanto, a consolidação da atividade turística depende da presença de diversos fatores que, reunidos, devem possibilitar uma "ambiência digna" ao turista, espelhando o modo como se devem atender as demandas da comunidade local. 


\section{CONSIDERAÇÕES FINAIS}

Os parques urbanos de Goiânia abarcam uma diversidade de valores e atributos, o que permite organizar uma série de reflexões acerca do desempenho desses espaços na dinâmica local.

Considerando os aspectos ambientais, a princípio, nota-se que os parques urbanos de Goiânia foram concebidos em áreas de nascentes e às margens de cursos d'água, o que implicaria não apenas na preservação da vegetação, uma das justificativas para a existência de parques urbanos, mas também dos recursos hídricos - algo que é pouco destacado.

Nessa concepção, foram idealizadas grandes áreas de mata e parques lineares, que contribuiriam para a salubridade de Goiânia ao mesmo tempo em que permitiriam a preservação da fauna e flora presentes nesses ambientes. Porém, com o processo de expansão do aglomerado urbano, muitas dessas áreas foram ocupadas e destinadas para outros fins, o que suscitou a redução da área dos parques, a fragmentação desses habitats, e, consequentemente, a redução da biodiversidade.

Além do desmatamento, outro fator que colaborou para a redução da diversidade biológica foi à introdução de espécies exóticas, que ocorreu nas primeiras décadas após a criação de Goiânia, pois, nesse período, a vegetação nativa não era valorizada. Hoje, considerando as falhas cometidas no passado, diversas intervenções urbanísticas buscam recompor os parques com espécies originárias, além dos projetos que procuram estabelecer conectividade entre as áreas verdes.

Além dos atributos físicos, outro elemento que merece destaque é a atuação dos parques na construção de espaços de valorização imobiliária. Tendo em vista que o processo de urbanização geralmente suscita outros processos como o aumento da densidade populacional, o crescimento do número de construções, a impermeabilização do solo e a redução dos espaços livres, observa-se que as áreas verdes tornam-se, cada vez mais, elementos exóticos na paisagem urbana. Esse aspecto, associado à crescente demanda por lazer e por melhor qualidade de vida, torna os parques urbanos espaços 
bastante valorizados na cidade, o que incita o interesse do setor imobiliário e da construção civil em edificar imóveis próximos a essas áreas, no sentido de agregar valor a seus empreendimentos.

Haja vista que esse processo exclui determinada parcela da sociedade, que possui menor poder aquisitivo, o poder público promoveu a criação de parques em diferentes regiões da cidade, inclusive em bairros periféricos. Mas, comparando o Bosque dos Buritis e o Parque Flamboyant ao Parque da Lagoa, foi possível notar que os parques de bairros de periféricos não recebem a mesma infraestrutura e tratamento daqueles situados em setores nobres.

A infraestrutura visivelmente superior, instalada nos parques urbanos de bairros nobres, associada à demanda por áreas aprazíveis de lazer, ainda escassas na maior parte de Goiânia, incitam as pessoas a se deslocarem de várias regiões de cidade para visitar parques como o Bosque dos Buritis e o Parque Flamboyant. No entanto a SEMTUR não vê isso como um problema, pois, segundo a secretaria, esse tipo de deslocamento promoveria o chamado turismo doméstico.

O Plano Municipal de Turismo de Goiânia 2009/2012, lançado no dia 04 de setembro de 2009, apresenta dentre seus programas o Projeto de Incremento do Turismo Doméstico, cujo principal objetivo é incentivar a prática do turismo entre os próprios moradores de Goiânia, para que também conheçam e desfrutem dos atrativos que o município oferece, permitindo, durante a baixa temporada, fomentar a cadeia produtiva do setor. O plano supracitado também apresenta um Projeto de Adequação e Criação de Espaços Turísticos, cujas estratégias incluem a adequação da infraestrutura dos parques urbanos, visando a sua utilização pelos turistas e pela comunidade local.

Considerando a opinião da população local expressa através da aplicação dos questionários, percebe-se que os parques urbanos desempenham um papel de grande relevância na dinâmica de Goiânia. No entanto, analisando comparativamente a infraestrutura e a forma de gestão dos parques, nota-se também a necessidade de implementação de políticas 
públicas eficientes que promovam o acesso equitativo ao lazer e a melhor qualidade de vida a toda a população goianiense.

Para o desenvolvimento do potencial turístico relacionado aos parques urbanos de Goiânia, ainda são necessárias inúmeras medidas que promovam e possibilitem a consolidação dessa atividade, nas quais devem se envolver diversas formas de solidariedade e de organização espacial, tais como a cooperação intermunicipal, a participação da comunidade e a parceria entre 0 público e o privado (ALMEIDA, 2004), com vistas à efetivação do Plano Municipal de Turismo, recentemente lançado.

Evidenciando a distinção nas obras e serviços realizados pelo poder público, que parecem variar de acordo com o poder aquisitivo da população beneficiada, espera-se não apenas contribuir para futuras pesquisas acadêmicas, mas principalmente fornecer subsídios para um melhor planejamento e execução de políticas públicas em Goiânia.

\section{REFERÊNCIAS BIBLIOGRÁFICAS}

ALMEIDA, M. G. Desenvolvimento turístico ou desenvolvimento local? Algumas reflexões. In: ENCONTRO NACIONAL DE TURISMO COM BASE LOCAL. Anais do VIII ENTBL - Planejamento para o desenvolvimento local, 2004, Curitiba. Disponível em: $<$ http://www.ufg.br/this2/uploads/files/214/Almeida maria geralda desenvolvim ento tur stico.pdf>. Acesso em 16.11.2009.

ALVAREZ, J. R. D. Geografia del turismo. Madri: Editora Síntesis, 1999.

ARRAIS, T. P. A. Goiânia: as imagens da cidade e a produção do urbano. In: CAVALCANTI, L. S. (org.) Geografia da Cidade: a produção do espaço urbano em Goiânia. Goiânia: Ed. Alternativa, 2001. p. 177-235.

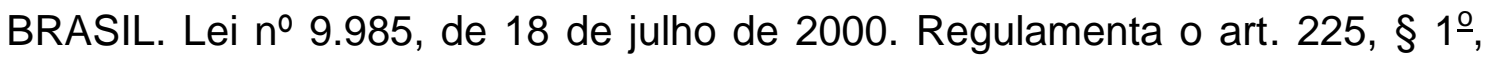
incisos I, II, III e VII da Constituição Federal, institui o Sistema Nacional de Unidades de Conservação da Natureza e dá 18.07.2000. Disponível em: $<$ http://www.planalto.gov.br/ccivil 03/Leis/L9985.htm>. Acesso em 15.11.2009.

COSTA, A. Novo Parque de Goiânia é Recebido com Festa pela População do João Braz e Região. Goiânia em Rede, Goiânia, 27 jun. 2008. Disponível em: $<$ http://www.goiania.go.gov.br/sistemas/snger/asp/snger01010r1.asp?varDt No ticia=27/06/2008\&varHr Noticia=10:44>. Acesso em 05.11.2009.

CRUZ, R. C. A. Introdução à geografia do turismo. São Paulo: Roca , 2003. 
DAHER, T. O Projeto Original de Goiânia. In: DOSSIÊ Cidades Planejadas na Hinterlândia. Revista UFG, Goiânia, Ano XI, oㅡ 6, 2009. p. 77-90.

FERREIRA, A. R. A Compreensão do Lazer no Planejamento Urbano de Goiânia: aproximações históricas. Dissertação de Mestrado apresentada à Faculdade de Educação Física da Universidade de Campinas. Campinas: [s.n.], 2003.

FUREGATO, M. C. H. Parque Urbano Orquidário Municipal de Santos/SP: equipamento de lazer e turismo. Revista Eletrônica Patrimônio e Lazer, São Paulo, 2005. Disponível em: $<$ http://www.unisantos.br/pos/revistapatrimonio/artigos.php?cod=36>. Acesso em 11.05.2009.

GOIÂNIA. Resgate do Berço Ecológico de Goiânia: atuação da SEMMA no período de 1993 a 1996. Goiânia: Ed. Kelps, 2007. Disponível em: < http://www.kelps.com.br/ecologia/arquivos/Resgate.pdf>. Acesso em 28.09.2009.

Parques e Bosques. Goiânia: AMMA, 2009. Disponível em: <http://www.goiania.go.gov.br/html/amma/index.htm>. Acesso em 17.08.2009.

GUZZO, P. Conceitos e Definições. São Paulo: USP, 1998. Disponível em: $<$ http://educar.sc.usp.br/biologia/prociencias/areasverdes.html>. Acesso em 04.09.2009.

HAMU, F. Parque Flamboyant Será Inaugurado no Sábado. Goiânia em Rede, Goiânia, 132 set. 2007.2 Disponível em: $<$ http://www.goiania.go.gov.br/sistemas/snger/asp/snger01010r1.asp?varDt No ticia=13/09/2007\&varHr Noticia=08:35 >. Acesso em 05.11.2009.

KLIASS, R. G. Parques urbanos de São Paulo. São Paulo: Pini, 1993.

LIMA, A. et al. Problemas de Utilização na Conceituação de Termos como Espaços Livres, Áreas Verdes e Correlatos. In: Anais do II CONGRESSO BRASILEIRO DE ARBORIZAÇÃO URBANA, São Luís/MA,1994. p. 539-553.

LOBODA, C. R.; DE ANGELIS, B. L. D. Áreas Verdes Públicas Urbanas: conceitos, usos e funções. Ambiência - Revista do Centro de Ciências Agrárias e Ambientais, Guarapuava, v.1, n.1, p. 125-139, jan./jun. 2005.

MACEDO, S. S.; SAKATA, F. G. Parques Urbanos no Brasil (Brasilian Urban Parks). 2 ed. São Paulo: Editora da Universidade de São Paulo - Imprensa Oficial do Estado de São Paulo, 2003.

MARTINS JÚNIOR, O. P. Uma cidade ecologicamente correta. Goiânia: AB Editora, 1996.

. Arborização Urbana \& Qualidade de Vida: classificação dos espaços livres e áreas verdes. Goiânia: Kelps/UCG, 2007. 
NUCCl, J. C. Qualidade Ambiental e Adensamento Urbano: um estudo de ecologia e planejamento da paisagem aplicado ao distrito de Santa Cecília (MSP). São Paulo: Humanista/FFLCH/USP, 2001.

OTTONI, D. A. B. Introdução. In: HOWARD, E. Cidades-jardins de amanhã. São Paulo: Ed. Hucitec, 1996.

RUSCHMANN, D. M. Turismo e planejamento sustentável: a proteção do meio ambiente. Campinas: Papirus, 1997.

SORENSEN, M. et al. Manejo de las áreas verdes urbanas: documento de buenas prácticas. Washington, D.C.: [s.n.], 1998.

ZMITROWICZ, W.; DE ANGELIS NETO, G. Infraestrutura Urbana. São Paulo: EPUSP, 1997.

YÁZIGI, E. A alma do lugar. São Paulo: Hucitec, 1996.

Vandalismo, Paisagem e Turismo no Brasil. In: YÁZIGI, E.; CARLOS, A. F. A.; CRUZ, R. C. A. (org.). Turismo: espaço, paisagem e cultura. 3르. Eão Paulo: Hucitec, 2002. p. 133-155. 